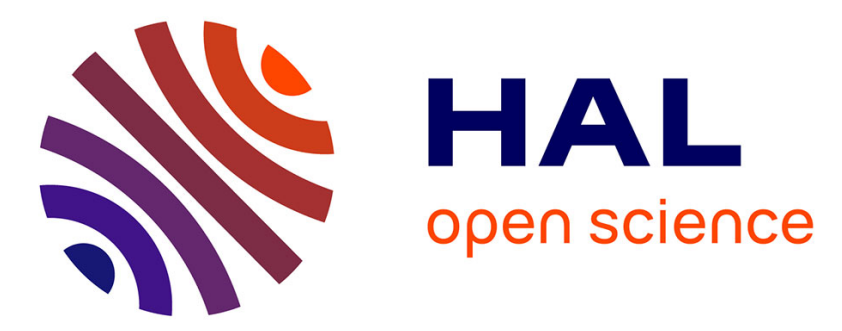

\title{
The design of the ITER first wall panels
}

\author{
R. Mitteau, B. Calcagno, P. Chappuis, R. Eaton, S. Gicquel, C. Jiming, A.
}

Labusov, A. Martin, M. Merola, R. Raffray, et al.

\section{To cite this version:}

R. Mitteau, B. Calcagno, P. Chappuis, R. Eaton, S. Gicquel, et al.. The design of the ITER first wall panels. Fusion Engineering and Design, 2013, 88 (6-8), pp.568 - 570. 10.1016/j.fusengdes.2013.05.030 . cea-02922289

\section{HAL Id: cea-02922289 https://hal-cea.archives-ouvertes.fr/cea-02922289}

Submitted on 26 Aug 2020

HAL is a multi-disciplinary open access archive for the deposit and dissemination of scientific research documents, whether they are published or not. The documents may come from teaching and research institutions in France or abroad, or from public or private research centers.
L'archive ouverte pluridisciplinaire HAL, est destinée au dépôt et à la diffusion de documents scientifiques de niveau recherche, publiés ou non, émanant des établissements d'enseignement et de recherche français ou étrangers, des laboratoires publics ou privés. 
Fusion Engineering and Design, Volume 88, Issues 6-8, 2013, Pages 568-570, ISSN 0920-3796,

https://doi.org/10.1016/j.fusengdes.2013.05.030

http://www.sciencedirect.com/science/article/pii/S0920379613004705

Keywords: Blanket; Plasma facing component; Design; Heat loads; ITER; Wall; Limiter

\title{
The design of the ITER first wall panels
}

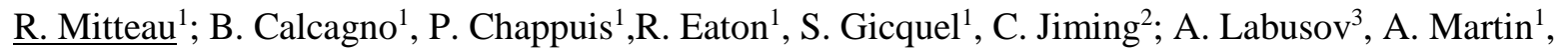 \\ M. Merola ${ }^{1}$, R. Raffray ${ }^{1}$, M. Ulrickson ${ }^{4}$, F. Zacchia ${ }^{5}$ and Blanket Integrated Product Team ${ }^{1}$ \\ ${ }^{1}$ ITER Organization, Route de Vinon sur Verdon, 13115 St. Paul lez Durance, France ; ${ }^{2}$ Southwestern \\ Institute of Physics, Huangjing Road, Chengdu 610225, China; ${ }^{3}$ Efremov Research Institute, 189631, St. \\ Petersburg, Russia; ${ }^{4}$ Sandia National Laboratory, Albuquerque, NM, USA; ${ }^{5}$ Fusion for Energy, Josep Pla 2, \\ Torres Diagonal Litoral B3, 08019, Barcelona, Spain
}

\begin{abstract}
The ITER blanket is in the final stage of design completion. The issues raised during the 2007 ITER design review about the First Wall (FW) heat loads and remote handling strategy have been addressed, while integrating the recently confirmed in-vessel coils. This paper focuses on the FW design, which is nearing completion. Key design justifications are presented, followed by a summary of the current status of the manufacturing plan and R\&D activities.
\end{abstract}

\section{Introduction}

The ITER blanket is a challenging in-vessel component since it fulfils many roles in a limited space: it exhausts the majority of the plasma heat power, it is the main contributor in providing neutron shielding for the superconducting coils and vessel structure, it provides a suitable plasma facing surface in the main vacuum chamber toward minimising plasma contamination, and, finally, it provides limiting surfaces that define the plasma boundary during start-up and ramp down [1]. The ITER blanket (Fig. 1) is now in the final stage of design completion. The overall design relies on modular blanket modules (BM). The blanket segmentation is basically the one of the ITER Final Design Review (FDR), with a radial thickness of about $0.5 \mathrm{~m}$, a toroidal width of 
1-2 $\mathrm{m}$ and a poloidal length of about1 $\mathrm{m}$. The concept of an 'in-vessel' separable FW panel mounted on the semi-permanent shield block (SB) is firmly established for simplifying the FW maintenance in case of damage. The design has evolved toward shaped FW panels to accommodate the actual plasma heat loads on the FW and to reduce heat loads on leading edges down to acceptable levels [2]. The $2-5 \mathrm{MW} / \mathrm{m}^{2}$ capability of the $\mathrm{FW}$ panels enables limiter operation directly on selected BM rows, and the problematic movable port limiters have now been abandoned. The progress of the design has highlighted new challenges: the large number of variants that need to be designed and managed (more than 100 variants are needed because of singularities caused by in-vessel coils, heating systems and diagnostics), and the delicate balance between conflicting requirements (design requirements are over-constrained). This paper focuses on the FW design, which is described in the next section. Key design justifications are briefly presented in section 3 , followed by a summary of the current status of the manufacturing plan and R\&D activities in section 4.

\section{First wall panel design}

The design of the FW panel is structured on a strong backing steel beam, oriented in the poloidal direction (Fig. 2.). The beam section is typically $350 \mathrm{~mm}$ (toroidal) x $150 \mathrm{~mm}$ (radial), over the entire poloidal length of the BM. The beam supports elongated plasma facing units, called 'fingers'. It also provides all interfaces to the SB (mechanical attachment, electrical conductors, water connection pipes). Connections are accessible from the front face, through a recess in the shaping that gives access to apertures up to $60 \mathrm{~mm}$ wide.

The beam is attached to the shield block by a unique $60 \mathrm{~mm}$ central bolt, located deep into the SB. The bolt design is a variant of the one for the BM flexible supports. It is preloaded to 200$700 \mathrm{KN}$, depending on the BM poloidal location. The bolt preload is reacted by four $60 \mathrm{~mm}-$ diameter compression pads, pressing the FW panel onto the SB surface. Four X-pads are embedded into the sides of the beam for reacting the radial torque, and vertical and lateral forces. Both bolt and pads are insulated from electrical currents by a $250 \mu \mathrm{m}$-thick alumina layer. The pads are designed so that the alumina layer is totally embedded into the FW structure, hence protected from direct impact when the pad operates with an assembly gap.

Water is fed directly from the BM coaxial connector to the FW through a 46mm-diameter connection pipe. Water is distributed into large inlet chambers which feed the finger circuits. 
Finger circuits are configured with 2 or 3 units in series, depending on the poloidal location, to achieve a water velocity of $2-3 \mathrm{~m} / \mathrm{s}$ in the finger circuits. The welds of the $\mathrm{FW}$ connection pipes to the SB are accessible from the plasma facing side through holes in the panel central slot. Remote handling gripping locations are also accessible from the plasma facing side to allow for in-vessel assembly and maintenance operations.

Two electrical straps provide a controlled electrical path to direct the electrical charge to the shield block in the presence of halo currents. The strap design is identical to the SB.

The plasma facing units consists of $0.5-0.9 \mathrm{~m}$ long fingers attached to the beam, in the toroidal direction with an overhang for full coverage of the shield block. The fingers are constructed using a composition of 3 main materials, $316 \mathrm{~L}(\mathrm{~N})-\mathrm{IG}$ austenitic steel for the structure, copper chromium zirconium $(\mathrm{CuCrZr})$ alloy for the heat sink and beryllium as armour material. A return water circuit provides cooling to the finger heat sink as well as to the structural steel.

The FW is shaped for minimizing the plasma heat load on edges caused by ports, diagnostic openings and assembly gaps between the FW panels. A detailed study of the plasma operation modes (plasma ramp up, flat top, ramp down) led to the retention of two categories of FW panels: a "normal heat flux" (NHF) technology, capable of accommodating 1-2 MW/m²; and an “enhanced heat flux" (EHF) technology capable of accommodating 4.7 MW/m². EHF fingers use a $\mathrm{CuCrZr}$ alloy heat sink, with a 40 x $5 \mathrm{~mm}$ hyper-vapotron, and are placed on blanket rows 3-45 for inboard plasma contact, 14-15-16-17 for outboard plasma contact and on rows 7-8-9 for accommodating the heat load to the top of the vessel during the flat top phase of the discharge. Rows 1-2-6-10-11-12-13-18 are equipped with NHF panels, whose fingers are made with a steel pipe liner embedded into a $\mathrm{CuCrZr}$ heat sink.

The detailed manufacturing route of both fingers and beam varies among the three procuring Domestic Agencies (China, Europe, Russia) and involves manufacturing technologies such as hot isostatic pressing (HIP), explosion bonding, brazing, and welding by e-beam, laser or TIG. The NHF beam is a steel box-like structure. The NHF manufacturing route involves a series of HIP cycles, producing successively the attachment of the beryllium to the fingers and the joining of the fingers to the beam. The EHF beam starts as a forged steel block that is conventionally drilled and milled for making the cooled structure. The fingers are manufactured by welding and brazing of the beryllium tiles and the finger are then joined onto the beam by welding. 


\section{Design justification and operation}

The main loads to the FW are the forces and moments caused by electromagnetic transient events and the thermo-mechanical cycling. Electromagnetic forces and moments are caused by poloidal and toroidal field variation and halo current during the disruptions and vertical displacement events (VDE). They are reacted by the combined bolt/pad system and transmitted to the SB. The largest load is the radial moment (up to $200 \mathrm{kN}$.m). It is reacted by the $\mathrm{X}$ pad system, which has a reaction arm of $1 \mathrm{~m}$, resulting in a local force of up to $200 \mathrm{kN}$ on the reaction faces of the shield block. The most constraining forces and moments to the FW attachment system are those resulting from a pulling force on the FW, namely a combination of radial pulling force $(30 \mathrm{KN})$ and poloidal and toroidal moments $(70 \mathrm{kN} . \mathrm{m}$ and $30 \mathrm{kN} . \mathrm{m}$, respectively). They are reacted by combined forces between the central bolt and compression pad. The shortest reaction arm is $250 \mathrm{~mm}$ for the poloidal torque. The bolt preload is set so that no opening of the radial pads occurs for Cat-II events. The design force on the pad is of $300 \mathrm{kN}$. The assembly of the FW to the SB involves an assembly gap (up to $0.4 \mathrm{~mm}$ at the X-pad), and radial pad opening may occur during the rare Cat-III events. The impact energy is up to $400 \mathrm{~J}$. While the mechanical behaviour of the pad metallic structure is demonstrated by analysis, design by experiment is needed (incl. impact test) for demonstrating the performance of the insulation layer over the design number of cycles (see section 4).

The overhanging fingers are also loaded by EM events. The reaction to the overhang is sustained by a backing structure linking the fingers to the central beam. The ability of the design to sustain the load is validated by analyses based on the design rules of the SDC-IC (for demonstrating compatibility with the planned 15000 cycle lifetime). Dynamic analyses are also undertaken for demonstrating that finger vibrations during EM events do not cause finger contact with the SB. Another significant design driver is the stress caused by the surface heat load to the finger and the nuclear heating of the beam. These are secondary stresses for which resistance to fatigue is demonstrated. The fingers are validated using both structural analyses for the structural part (the steel support) and 'design by experiment' for the beryllium bonding and the bronze part.

\section{R\&D and qualification}

The FW qualification program is increasingly focused toward actual prototypes. Small scale mock-ups have demonstrated the adequateness of the beryllium to copper bonding technology to 
$1 \mathrm{MW} / \mathrm{m}^{2}$ for up to 15,000 cycles. The specimens were actually tested for a few hundred cycles at 2.5 times the design heat load [3 and Fig. 3], demonstrating the robustness of the bonding technique. The brazed EHF bonding technology has been endurance-tested for 7500 cycles at 4.7 $\mathrm{MW} / \mathrm{m}^{2}$ followed by 1500 cycles at $5.9 \mathrm{MW} / \mathrm{m}^{2}$. A program to confirm the $2 \mathrm{MW} / \mathrm{m}^{2} \mathrm{NHF}$ technology is currently underway. Semi-prototypes $(0.6 \mathrm{~m}$ long, 6 fingers wide attached to a beam section) are being manufactured for both normal and enhanced heat flux technologies, with the goal of demonstrating the fabrication route of shaped fingers attached to the beam. The semiprototypes are also aimed at confirming the adequateness of bonding technology for a large number of tiles. On the longer term, the full scale prototype (FSP) activities have started. The design of the NHF FSP is finalised, and its manufacture and testing will aim at confirming at the prototypical scale interfaces to the SB, manufacturing tolerances (both at the surface with the beryllium tiles, and to the FW/SB mechanical interface), acceptance test and the setting up of the manufacturing and quality documentation.

Supporting R\&D activities are gradually tapering down as the qualification program is increasingly oriented toward real size components. Recent progress includes the confirmation of the critical heat flux database for FW relevant thermo-hydraulic parameters (velocity of 2-4 m/s, pressure of 3-4 $\mathrm{MPa}$ and inlet temperature of $70^{\circ} \mathrm{C}$ ) and the confirmation of the baseline tile size (40 mm x $40 \mathrm{~mm}$ for the NHF fingers, $16 \mathrm{~mm} \times 16 \mathrm{~mm}$ for the EHF one). Other programs are still on-going, like the update of the remote handling tooling and procedures (gripping tool, welding of connection pipes), determination of acceptance criteria for the $\mathrm{Be} / \mathrm{CuCuZr}$ interface, confirmation of edge heat load allowance for the $\mathrm{Be} / \mathrm{CuCrZr}$ bonding, irradiation mock-ups, performance demonstration of alumina insulation coating, investigation toward high performance insulation coatings. Part of these activities will extend into the procurement phase which is necessary to achieve the project schedule.

\section{Conclusion}

The ITER blanket is in the final stage of design completion. The issues raised during the 2007 ITER design review about the FW heat load and remote handling strategy have been addressed, while integrating the recently confirmed in-vessel coils. The blanket shield block and FW are the last major components of ITER being finalised. This is a large effort given the complexity of the component (more than 100 variants) and the large number of constraints (mechanical loads, 
thermal energy, limited space, frozen interfaces) which must be met. Supporting R\&D activities are gradually tapering down as the manufacturing program is being oriented toward actual size components.

\section{Disclaimer}

The views and opinions expressed herein do not necessarily reflect those of the ITER Organization

\section{References}

[1] Overview of the Design and R\&D of the ITER Blanket System, A. Rene Raffray, M. Merola, and Contributors from the ITER Blanket Integrated Product Team, to be published in Fus. Eng. Des.

[2] Heat loads and shape design of the ITER first wall, R. Mitteau, P. Stangeby, C. Lowry, et Al., Fus. Eng. Des3, 85, 10-12 (December 2010) 2049-2053.

[3] High heat flux testing of beryllium components with improved diagnostics, C. Thomser, A. Schmidt, B. Bellin, et Al., Fus. Eng. and Des., Volume 86, Issues 9-11, October 2011, Pages 2409-2412

[4] Russian development of enhanced heat flux technologies for ITER first wall, I. Mazul, A. Alekseev, V. Belyakov, et Al., Fus. Eng. Des, In Press.

[5] Preparation to manufacturing of ITER plasma facing components in Russia, I.V. Mazul, V.A. Belyakov, R.N. Giniatulin, Fus. Eng. and Des., Volume 86, Issues 6-8, October 2011, Pages 576-579.

\section{Figures}

Fig 1 : ITER first wall panels inside the vessel

Fig 2 : View of the first wall panel of Blanket Module 1

Fig. 3 : Picture of mock-up OHV50-3 after testing. 
Fig. 1

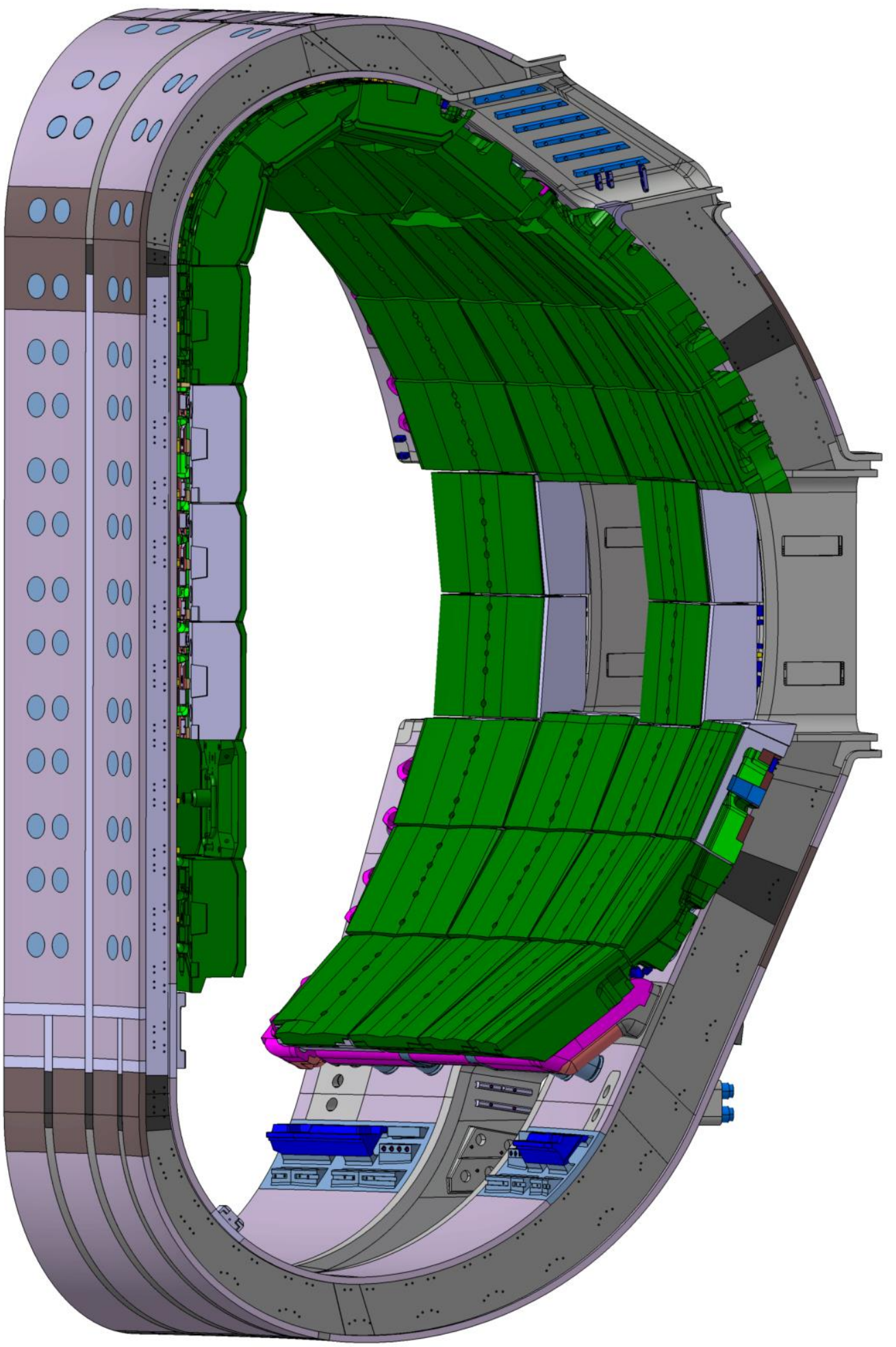


Fig. 2

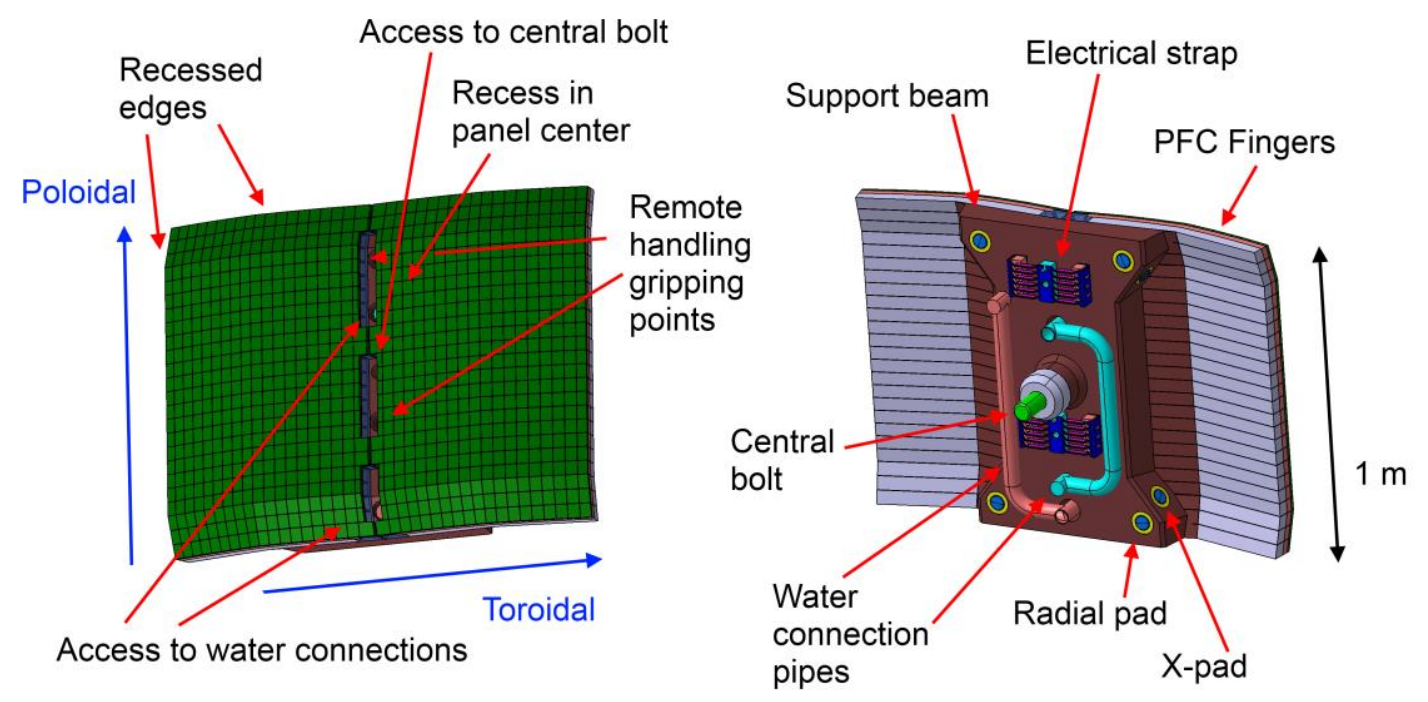


Fig. 3

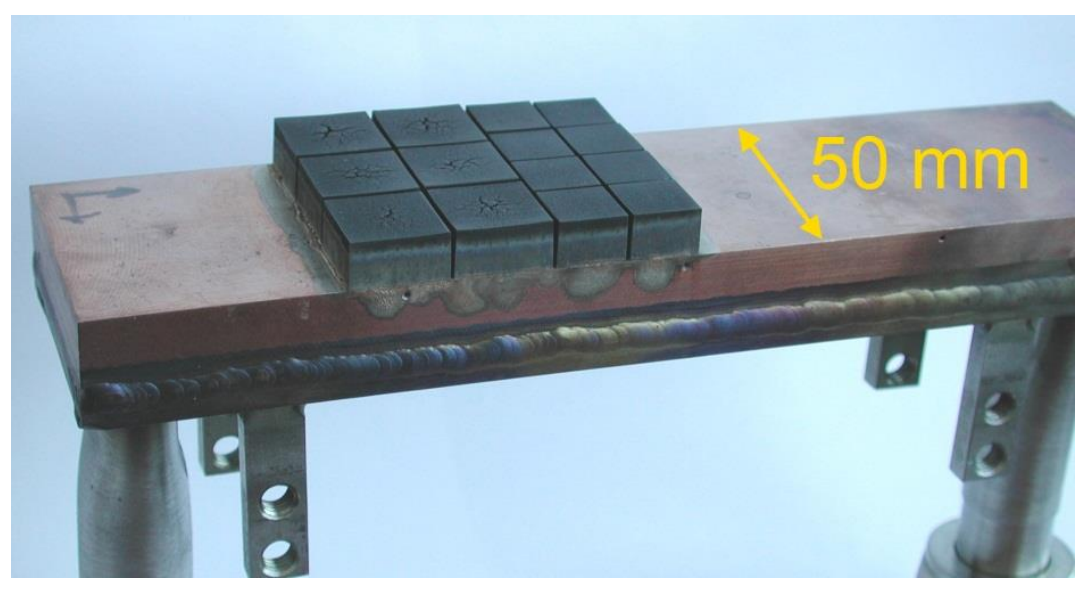

